\title{
Representação de Patrimônio a partir do Desenho Paramétrico como Processo Formativo para o Projeto
}

\author{
Heritage Representation from Parametric Design as Formative Process for the Project
}

\author{
Adriane Borda Almeida da Silva \\ UFPel, Brasil \\ adribord@hotmail.com
}

\author{
Valentina Toaldo Brum \\ UFPel, Brasil \\ valentinatbrum@hotmail.com
}

\begin{abstract}
This study regards the structuring of educational activities to promote and investigative attitude towards underlying geometric logic of formal organization in architectural design processes. It combines the purpose to build knowledge about architecture of heritage interest. Interprets the parametric design techniques as an opportunity to expand the exercises of redesign, focusing on geometric parameters traditionally used to link architecture to music, such as the proportional relationships with rhythms and harmonies. To do so, an exercise of representation of a specific object is used, seeking to contribute to the teaching practice in the area of geometry, representation and the early stages of training in architectural design.
\end{abstract}

Keywords: Parametric Design; Heritage; Representation; Geometry. Music Architecture

\section{Introdução}

O exercício de representação de um patrimônio arquitetônico que aqui se relata, embora possa vir a contribuir para a valorização e construção de conhecimento específico sobre o objeto representado, está centrado, especialmente, no propósito de investigar sobre lógicas geométricas subjacentes à organização formal em processos projetuais de arquitetura.

De acordo com Sainz (1990), a postura de investigação estava implícita nas atividades de representação das oficinas renascentistas e das academias barrocas. Os estudantes dissecavam obras exemplares de arquitetura por meio do desenho de observação como modo mais efetivo para compreender e se aproximar da prática projetual. Este método era considerado apropriado para descobrir inspirações e resoluções utilizadas pelos arquitetos para solucionar os problemas projetuais. Após a cópia, os estudantes passavam a compor variações, combinando suas ideias com as do autor da obra, obtendo assim novos projetos.

Para Sainz (1990), esta exploração de variações sobre um tema dado se assemelha a um processo de composição musical, considerando um dos exercícios com maior conteúdo didático para a arquitetura. Com esta comparação, se utiliza do propósito de interpretar um projeto como uma partitura. Refere-se assim à capacidade do projeto em nos fazer conhecer uma melodia, ainda que não estejamos escutando. Sob este propósito, o redesenho tem a intenção de comprovar hipóteses de como foram configurados ritmos e harmonias na composição para aprender com isto e então saber variar notas, tons e gerar novos acordes.

Rocha (2011) revisa a fundamentação teórica e procedimental envolvida neste tipo de abordagem junto à prática de arquitetura, referindo-se à Teoria Matemática do Belo. Reúne elementos que explicam esta lógica de associar a arquitetura com a música. Destaca que a estruturação numérica do mundo, mencionada por Vitrúvio, consiste na harmonia das proporções adequadas, remontando às fontes pitagóricas. Lembra que Pitágoras identifica relações numéricas entre os intervalos musicais, representando-as por meio da divisão de um segmento em partes proporcionais. Exemplifica, referindo-se à vibração de uma corda, que em uma oitava a divisão equivale ao fracionamento de um segmento em dois, dispondo, portanto, das relações $1 / 2$ e o oposto, 2/1. Com esta maneira didática demonstra procedimentos gráficos que instrumentalizam os estudos analíticos, ressaltando que em uma concepção pitagórica, a associação de escalas musicais com proporções visuais, está diretamente ligada ao conceito de harmonia. $\mathrm{O}$ autor também faz notar que esta ideia de haver uma correspondência entre a consonância audível dos intervalos musicais pitagóricos com a consonância visual do ritmo arquitetônico explica a expressão "música congelada" atribuída por Goethe à Arquitetura.

No contexto formativo em que se desenvolve este trabalho há poucos anos se conseguiu formalizar o conceito de proporção junto ao resgate do estudo de geometria plana em disciplinas de geometria e representação. Estes conteúdos estiveram presentes somente nos dois primeiros anos de funcionamento do Curso de Arquitetura da UFPel. Criado em 1972, no meio de uma Escola de Belas Artes, logo houve o movimento para abrir um maior espaço para a formação técnica associada às Engenharias, reduzindo a carga horária de desenho. Tudo isto foi paralelo aos reflexos da LDB/71, quando, de acordo com Kopke, 2009, o desenho deixou de ser disciplina para ser caracterizado como "conteúdo relativo às artes e ao estudo da matemática". Isto ficou a cargo dos professores de Educação Artística que "privilegiaram a criatividade ou o desenho livre, apenas como atividade 
lúdica". A geometria, no âmbito da matemática, passou a ser lecionada desconectada de sua representação gráfica. No Brasil, de acordo com Bueno, 2015, mesmo após a LDB/96, o ensino de desenho em nível básico é quase inexistente. Afirma que, raramente, um estudante, durante sua passagem pela escola pública, terá solucionado um problema de geometria de maneira gráfica, desconhecendo o campo da geometrografia. O referido autor atribui esta redução da geometria, no âmbito da disciplina de Matemática, à "adoção dos princípios e práticas da Matemática Moderna”, na década de 60.

Junto à área de representação, a geometrografia foi impulsionada com o desenvolvimento das tecnologias digitais, especialmente por estas ferramentas facilitarem aos profissionais leigos em linguagens de programação o uso de processos dinâmicos e associativos, de geração e controle da forma de maneira precisa. No Brasil, diversas ações didáticas (BRAVIANO, ULBRICHT e VIEIRA, 1996; RODRIGUES, 2005; RODRIGUES e RODRIGUES, 2013), registradas junto aos fóruns promovidos pela Associação Brasileira de Expressão Gráfica (ABEG), há mais de uma década, exemplificam o investimento em ferramentas digitais para a geometrografia dinâmica. $E$, recentemente tem-se a disponibilização deste tipo de recurso junto às ferramentas digitais já estabelecidas em práticas profissionais de arquitetura, como são as apropriadas para o que se tem nomeado como desenho paramétrico (KOLAREVICH, 2003).

Oxman, 2006, define o desenho paramétrico como uma técnica para a geração de modelos associativos. As relações entre os elementos são explicitamente descritas, estabelecendo interdependências entre os objetos. A atribuição de diferentes valores aos parâmetros determinados podem gerar múltiplas variações, mantendo as condições topológicas da forma (OXMAN, 2006).

A modelagem paramétrica se desenvolve em ambientes digitais e se utiliza de algoritmos para a construção de definições. Segundo Terzidis, 2006, algoritmos são entendidos como procedimentos para abordar problemas em um número finito de etapas, envolvendo a extração de princípios lógicos. Neste sentido, envolvem dedução, indução, abstração, generalização e uma lógica estruturada.

O desenvolvimento de todas estas habilidades citadas por Terzidis, 2006, é preconizado pelo estudo da matemática, tendo na geometria um campo próprio por apoiar-se em princípios lógicos.

Em Pereira e Vaz (2013), como exemplo, encontra-se o registro de práticas brasileiras de redesenho de arquitetura, a partir de técnicas de desenho paramétrico. Diversas obras de Félix Candela foram representadas utilizando-se da parametrização de paraboloides hiperbólicos, buscando compreender os procedimentos projetuais adotados para as composições formais. Interpreta-se este tipo de trabalho como uma releitura das atividades desenvolvidas pelas oficinas renascentistas e barrocas, por também envolver uma postura de investigação por meio da representação.
Entretanto, extrair os princípios lógicos de uma determinada configuração formal e poder comprová-los, utilizando-se de técnicas de desenho paramétrico, exige o reconhecimento de elementos que conectem a linguagem algébrica com a gráfica, avançando assim no exercício de redesenho.

Estabelecer este tipo de prática junto ao contexto de graduação, caracterizado anteriormente e problematizado pelo perfil dos estudantes em relação aos conhecimentos prévios em geometrografia, se configura como um desafio. Isto passa a indicar a necessidade de adicionar conteúdo ao ato de representar/criar/projetar. Conteúdo que seja capaz de extrair lógicas geométricas que tenham sido estruturadas para a resolução de problemas projetuais de arquitetura.

Neste trabalho, busca-se então utilizar o conceito de desenho paramétrico para tratar de conteúdos que muitas vezes ficam no plano figurativo, tais como alguns princípios clássicos, como ritmo, regularidade, simetria e proporção. A atividade busca a estruturação de práticas de representação, ressaltando questões concernentes à geometria, quando é utilizada propositalmente para atribuir hierarquia, caráter, unidade e harmonia à arquitetura.

Deve-se destacar que este estudo busca atender objetivos traçados no âmbito de dois projetos: Projeto MODELA Pelotas, o qual adota o patrimônio arquitetônico de interesse patrimonial da cidade de Pelotas como objeto de referência para estudos de representação e Projeto ACORDA, o qual investe na análise e construção de referenciais didáticos para a inserção do desenho paramétrico e prototipagem rápida na formação em arquitetura. Desta maneira, a atividade de redesenho a ser registrada quer contribuir para a ampliação de métodos de construção de conhecimento sobre o patrimônio representado, apoiar as atividades docentes de inserção de técnicas de desenho paramétrico no contexto de graduação referido e, com isto, contribuir com a formação para a ação projetual de arquitetura, no âmbito de disciplinas de geometria e representação.

\section{Metodologia}

A etapa de seleção dos objetos a serem estudados está sendo guiada pela vigência de um acordo com a Prefeitura Municipal de Pelotas, a qual tem apontado necessidades e facilitado o acesso à documentação precisa. Por parte da UFPel, existe o compromisso em disponibilizar os resultados para uso, sem fins lucrativos, em ações culturais, turísticas e educativas.

O método de representação empregado foi delimitado apoiando-se na descrição de Terzidis, 2006 sobre os procedimentos para a extração dos princípios lógicos que envolvem o desenvolvimento de um desenho paramétrico: dedução, indução, abstração, generalização e uma lógica estruturada. Frente ao propósito de introduzir a parametrização por meio de atividades de redesenho, focando na geometria, o estudo parte da execução de análises gráficas, do mesmo tipo das apresentadas em Rocha, 2011. Sendo assim, trata de identificar, na forma dos objetos arquitetônicos de interesse patrimonial, a rigidez ou 
não no uso de proporções e regras compositivas determinadas. Associa-se esta etapa ao emprego de procedimentos dedutivos, de demonstração por meio de traçados, e ao emprego de procedimentos indutivos, os quais verificam se existe alguma correspondência entre a lógica de associar intervalos musicais a um suposto ritmo arquitetônico atribuído pela forma do objeto analisado.

Em um segundo momento as relações identificadas são formalizadas por meio das técnicas de programação visual, próprias do desenho paramétrico. Esta etapa, de redesenho propriamente dito, refere-se à abstração. Um exercício de reconhecimento das correspondências entre a linguagem gráfica e algébrica, pouco explorada no contexto de formação em questão. Desta maneira, adiciona ainda a necessidade de apropriação das ferramentas específicas de desenho paramétrico, neste caso o uso do software Rhinoceros associado ao editor algoritmico Grasshopper. Junto a este processo se estabelece a etapa de generalização, a partir da comprovação das hipóteses que buscam a compreensão do processo de estruturação de lógicas determinadas.

\section{Resultados}

Foi realizado um primeiro exercício de representação valendo-se da conveniência de utilizar uma obra sobre a qual já haviam sido executados, em trabalho anterior (Brum et al, 2015), um modelo digital tridimensional e maquetes físicas por processos de fabricação digital. Estas representações foram desenvolvidas a partir de uma documentação arquitetônica precisa cujo acesso foi facilitado pela Prefeitura Municipal de Pelotas.

A obra refere-se a uma estrutura em ferro do século $\mathrm{XIX}$, o Reservatório R1 (Figura 01), localizado na Praça Piratinino de Almeida, na cidade de Pelotas. Este reservatório é sustentado por uma estrutura pré-fabricada de peças em ferro fundido, ornadas com consoles, grades, molduras e arcos. Apresenta planta circular, volume cilíndrico e capacidade para $1500 \mathrm{~m}^{3}$ de água. Na parte superior há um torreão, cujo acesso se dá por meio de uma escada helicoidal, caracterizando-se como um mirante. Este reservatório é um dos quatros bens tombados pelo Instituto do Patrimônio Histórico e Artístico Nacional (IPHAN) na cidade de Pelotas, portanto ressalta-se sua relevância.

A partir de Gomes (1986) compreende-se o contexto em que este tipo de obra foi produzido. Refere-se à Primeira Revolução Industrial, com a disseminação do processo de fundir o ferro e a consequente redução de custos de produção. Isto propiciou ao campo da construção da época, uma série de inovações, incluindo: a produção de componentes arquitetônicos, produzidos e reproduzidos por meio de fôrmas e a possibilidade de venda em catálogos; facilidade de transporte; transparência e leveza, que contribuíram para a quebra da rigidez; e possibilidade de montagem e desmontagem dos elementos que compõem a edificação. O momento, hoje reconhecido como Arquitetura do Ferro, caracterizou-se pelo uso indisfarçado do material, não somente como estrutura, mas também dando identidade a uma linguagem.

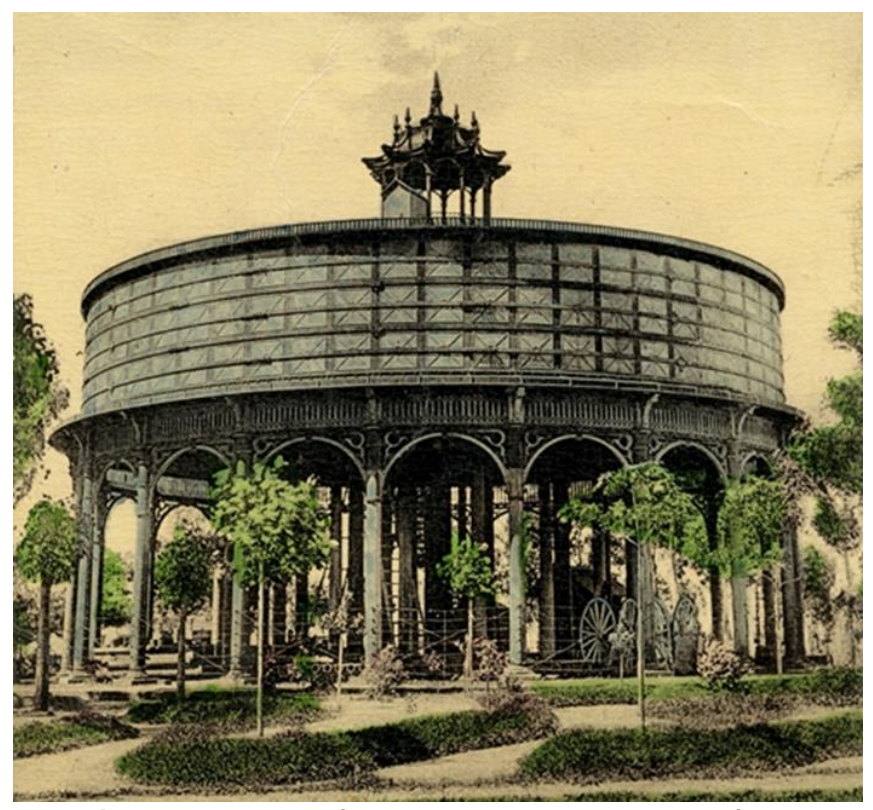

Figura 01: Reservatório R1 em um cartão postal da época de 1912.

Fonte: Acervo Arthur B. Matte

O Reservatório R1 foi erguido em Pelotas no ano de 1875, tendo sido comprado por catálogo, da empresa Hanna Donald \& Wilson Makers, Abbey Works, localizada na cidade de Paisley, Escócia. Consta no noticiário da época, da cidade de Pelotas, que a instalação deste elemento trouxe consigo os ideais industriais e de progresso, assim como os princípios da arquitetura em ferro (conforme informações acessadas junto ao site oficial do órgão responsável por este patrimônio: Serviço Autônomo de Saneamento de Pelotas, SANEP).

De acordo com o método de representação proposto, a análise geométrica gráfica da obra em questão foi realizada sobre as plantas baixas, cortes, fachadas e fotografias, identificando-se regras compositivas clássicas, tais como simetrias, recursões, uso de proporções e tripartição.

A presença da tripartição já pode ser observada junto à planta baixa (Figura 02), existindo três conjuntos de colunas concêntricas, estabelecendo, pela repetição e rotação de $360^{\circ}$, um ritmo uniforme sobre qualquer ponto de vista. Conforme Rocha (2011), a divisão de um elemento em três partes pode ser relacionada ao princípio platônico da existência de três princípios eternos que constituem o todo: ideias reais (arquétipo de tudo o que se cria), demiurgo (age como organizador do mundo) e matéria (receptáculo das formas criadas).

Ainda sobre a planta observa-se a associação entre as partes: as sequências de colunas de raio médio e raio maior 
apresentam razão raiz de três, indicando o propósito de que esta razão possa garantir uma composição harmônica.

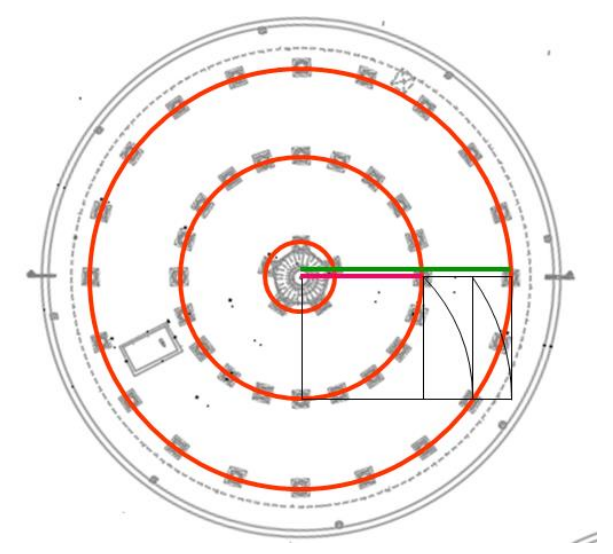

Figura 02: Relações de tripartição e proporção em planta baixa no Reservatório R1

Fonte: Autoras

Estas estratégias também ficam evidentes na composição das fachadas. Os esquemas da esquerda da Figura 3 ressaltam a tripartição em altura. Os esquemas da direita destacam as relações proporcionais. Demonstra-se que a altura da parte cilíndrica do corpo do reservatório está para a altura das colunas, assim como todo torreão está para o restante de sua altura em uma razão áurea. O uso desta razão, ainda que repleto de cargas místicas e simbólicas, é tido como recurso geométrico de ordenamento e mostra a possibilidade de uma evolução guiada (LAWLOR, 1996). A sequência numérica identificada corresponde ao traçado geométrico da proporção áurea, referindo-se à progressão de Fibonacci. Observa-se também, no torreão, que a altura das colunas corresponde à altura da coroa e também a do pináculo. Com a identificação destas relações fica evidente a estratégia de atribuir harmonia ao conjunto destes elementos valendo-se de um repertório de razões, não somente a de raízes como a áurea.

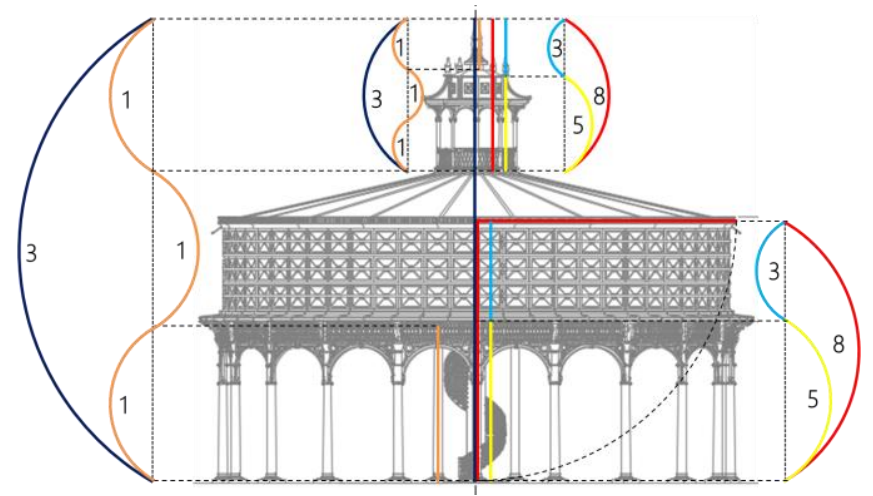

Figura 03: Relações de tripartição e razão áurea no Reservatório R1 Fonte: Autoras

Como demonstrado na Figura 04, verifica-se a recorrência de retângulos dinâmicos e áureos, caracterizados como polígonos envolventes de partes dos elementos assim como do todo, seja do corpo torreão (raiz de 3 ) ou do reservatório propriamente dito (raiz de 2). Sobre as partes do torreão, revelam-se retângulos: raiz de dois, áureos, áureos recíprocos e duplo quadrado (raiz de quatro).
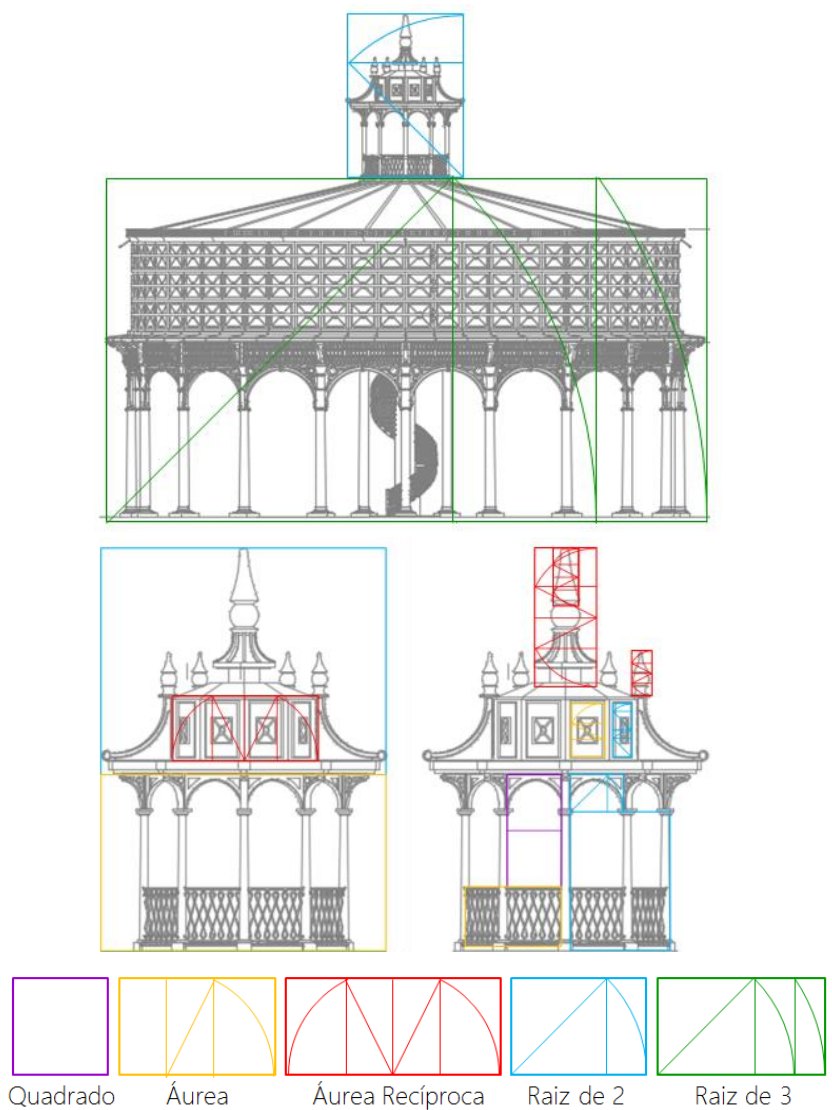

Figura 04: Caracterização de polígonos envolventes Fonte: Autoras

A ideia de ordenamento da composição pode ser interpretada a partir da relação com uma oitava da escala musical. Verifica-se a existência de relações dois para um, ou o seu oposto, ilustradas na Figura 05. A altura das colunas internas equivale ao dobro da altura do corpo do reservatório, e no torreão, a altura do pináculo ou a altura da coroa correspondem à metade da sua distância dos gradis de guarda corpo até a base do pináculo. 


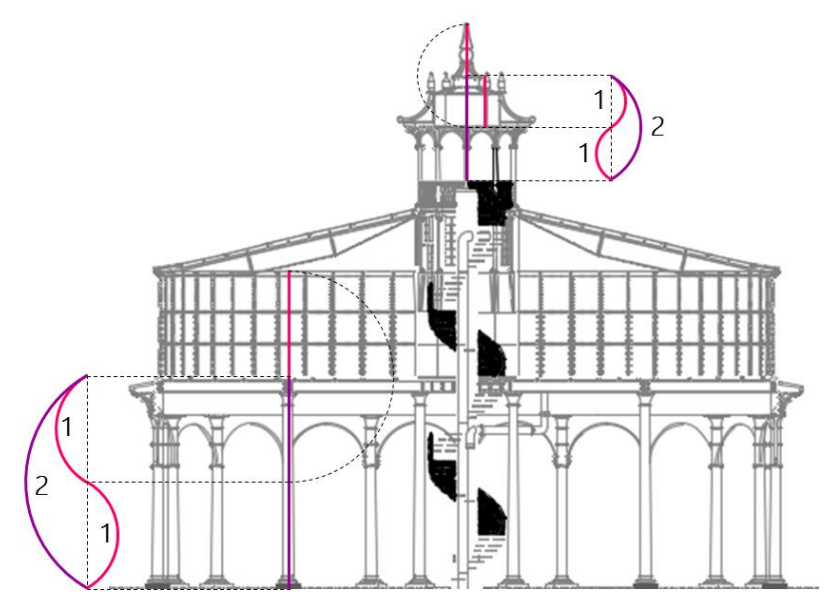

Figura 05: Relações equivalentes a oitava musical Fonte: Autoras

$\mathrm{Na}$ etapa de abstração (parametrização), foram considerados, como ponto de partida, três parâmetros principais para o redesenho: o raio do reservatório (radius), o número de colunas que o sustentam (count) e a altura destas colunas (variable z), conforme ilustrado pela imagem da esquerda da Figura 06. Estes mesmos parâmetros são utilizados como variáveis em operações algébricas para a derivação de valores que dimensionam outros elementos. Com a imagem da direita da Figura 06 exemplifica-se uma destas operações, a qual implementa uma das restrições para o estabelecimento da proporção áurea, a partir da divisão de uma variável x pela constante algébrica $\varphi$ (phi).
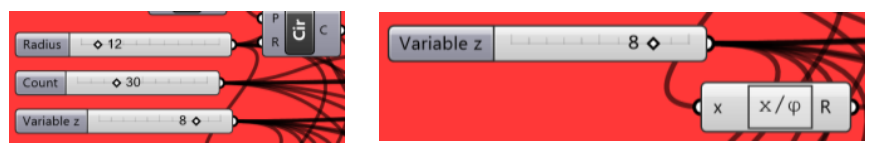

Figura 06: Á esquerda: raio, número de colunas e altura das colunas definidos a partir de "slider bars", parâmetros numéricos deslizantes. À direita: Operação algébrica de divisão de uma variável numérica pela constante $\varphi$ (phi) Fonte: Autoras

A definição paramétrica, ilustrada na Figura 07 , corresponde à identificada no objeto, a qual utiliza os valores: 12 para o raio, 20 para o número de colunas e 8 para a altura das colunas, valores obtidos a partir da documentação arquitetônica. Estes valores dimensionais determinam a proporção áurea aproximada.

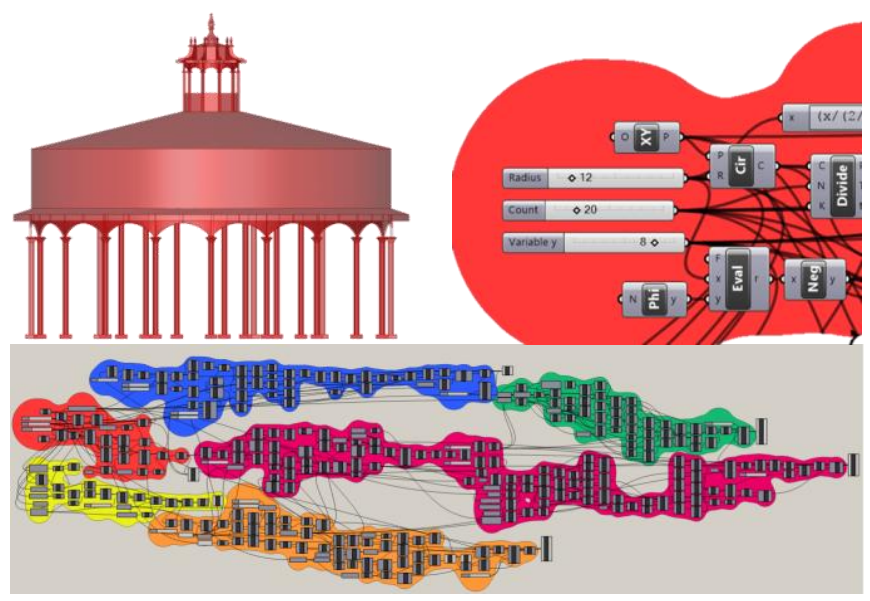

Figura 07: à esquerda, acima, o modelo digital parametrizado, com os valores identificados na obra. À direita e abaixo, os esquemas de programação visual utilizados para o desenho paramétrico Fonte: Autoras

Na Figura 08 são ilustradas soluções nas quais são alterados cada um dos três parâmetros de maneira isolada: raio, número de colunas e altura delas, respectivamente. Nitidamente observa-se a descaracterização da harmonia da composição, tendo em vista que estes parâmetros foram alterados aleatoriamente, sem as restrições identificadas anteriormente.

O exercício, ainda em desenvolvimento, avança para implementar todas as restrições geométricas identificadas nos desenhos bidimensionais, buscando uma reprodução precisa da lógica compositiva da obra.
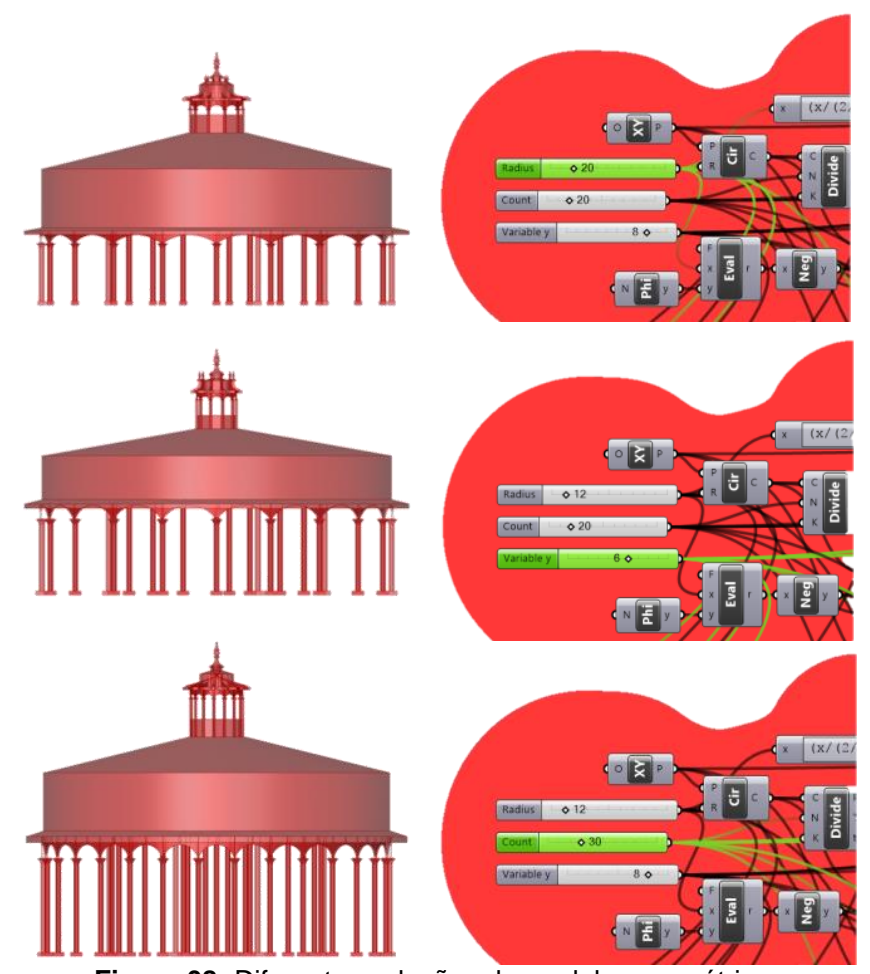

Figura 08: Diferentes soluções do modelo paramétrico Fonte: Autoras 


\section{Discussão}

O objeto de estudo se mostrou pertinente para introduzir o exercício de uso de instrumentos gráficos, como os apontados em Rocha (2011), para a compreensão de ritmos e harmonias utilizados para compor as formas envolvidas. 0 fato de existir uma lógica implícita, a partir de regras geométricas associadas aos compassos musicais, permite exemplificar um objeto derivado de um processo projetual rigidamente controlado por determinadas relações proporcionais.

O uso do desenho paramétrico exigiu explicitar tais relações que atribuem ao objeto característica associativa, nos termos de Oxman, 2006. Foi possível extrair as interdependências entre as partes e os valores atribuídos aos parâmetros para "congelar" (Goethe) uma instância específica da condição topológica da forma em questão.

Ainda, nos termos de Terzidis, 2006, o exercício com a parametrização promoveu a dinâmica de transitar entre procedimentos dedutivos (as construções gráficas) e indutivos (as associações). O exercício exigiu avançar no desenvolvimento da capacidade de abstração, referindo-se à formalização das operações matemáticas a serem empregadas para estabelecer as associações entre as partes do modelo. Motiva o questionamento sobre a possibilidade de generalização dos procedimentos projetuais identificados, tendo em vista o contexto em que se insere este patrimônio, em que há inúmeros artefatos em ferro que compõem a arquitetura eclética da cidade. E, por fim, permitiu identificar uma lógica estruturada, que explica em termos geométricos os procedimentos compositivos empregados. Com isto é possível compreender as estratégias para lograr ritmos e harmonias determinados por meio da forma.

Desta maneira, este tipo de redesenho se constitui como uma ação de investigação. Neste caso, sobre o Reservatório $\mathrm{R} 1$, produto de um projeto, para a escala industrial e de catálogo, próprio do momento da "arquitetura do ferro". Neste processo, explicitou elementos que explicam a atribuição de harmonia, ritmo, equilíbrio e beleza à obra, somando informações históricas e técnicas sobre este patrimônio, promovendo sua leitura mais precisa e valorização. Entretanto, para o contexto no qual se insere, ele se constitui principalmente como investigação no campo da didática para o projeto de arquitetura. O material produzido demonstra uma maneira de introduzir as técnicas de desenho paramétrico, cujos parâmetros podem ser de diversas naturezas, a partir do método abstraído de Terzidis (2006). Embora, tratando apenas da geometria, insere outra postura, na medida em que o exercício tem exigido revisitar procedimentos projetuais clássicos, gráficos, para traduzi-los por meio da álgebra. Junto ao aprendizado de geometria e tecnologias de representação estas práticas de redesenho podem promover a construção de um olhar mais atento para a percepção das lógicas subjacentes de composições arquitetônicas, adicionando conteúdo formativo em relação às práticas de representação, seja do desenho de observação, técnico ou de modelagem tradicionais.

\section{Conclusões}

Nos termos de Sanz, 2009, reforça-se a consideração de que o redesenho seja um dos exercícios de maior conteúdo para a iniciação em arquitetura. Considera-se também que a partir do desenho paramétrico esta atividade pode ser potencializada pela possibilidade de se valer de procedimentos interativos que permitem "congelar" diversificadas instâncias controladas por parâmetros que podem ir muito além dos aspectos formais. Este tipo de redesenho mostra-se como uma ferramenta que permite dissecar e comprovar as hipóteses do pensamento de projeto de uma obra específica. É um instrumento preciso de investigação.

Desta maneira, além deste estudo contribuir para reunir informações técnicas e históricas acerca do Reservatório R1, entende-se que o redesenho que está sendo realizado se revela apropriado não para o ensino de regras, mas para a compreensão de métodos, de estratégias empregadas para a delimitação da forma arquitetônica.

\section{Agradecimentos}

Este estudo faz parte das atividades da segunda autora como bolsista de iniciação científica, CNPq, junto ao Projeto ACORDA (Análise e Construção de Referenciais Didáticos para Arquitetura: uma abordagem para 0 desenho paramétrico e para a prototipagem rápida). O trabalho contou com consultorias dos Professores MSc. Luisa Della Vecchia/FAURB/UFPel e Dr. Carlos Eduardo Vaz/FAU/UFSC.

\section{Referências}

Braviano, G.; Ulbricht, V.; Vieira, M. O uso do Cabri-Géométre no Ensino de Desenho Geométrico. In Anais do XII Simpósio de Geometria Descritiva e Desenho Técnico, Florianópolis, v.1, p.508-517, 1996, bianual.

Bueno, M. S. Quem, afinal, nas escolas brasileiras, promove o desenvolvimento das competências gráficas? In: III APROGED'S International Conference [e] XI International Conference ond Graphics Engineering for Arts and Design. 2015, Lisboa. Anais eletrônicos... Porto: APROGED. 2015. p. 477-487

Gomes, G. Arquitetura do Ferro. Resenha da pesquisa "Arquitetura do Ferro Fundido na América Latina, Caribe e Antilhas", Edição 90, Junho 2000, disponível em http://au.pini.com.br/arquiteturaurbanismo/90/arquitetura-do-ferro-24331-1.aspx Acessado em 03/04/2016

(1986). Arquitetura do ferro no Brasil. São Paulo: Nobel.

Kopke, R. C. M. Objetos esculpidos e a visão espacial. VIII International Conference on Graphics Engineering of Arts and Design e XIX Simpósio Nacional de Geometria Descritiva e Desenho Técnico. 2009, Bauru. Anais eletrônicos... Bauru: UNESP. 2009. p. 869-881

Oxman, R (2006). Theory and design in the first digital age. In: Design Studies 27. London: Elsevier. 
Pereira, N. S.; Vaz, C. E. (2013). Parametricismo e Ensino de Geometria - As superfícies de Félix Candela. Graphica 2013, Florianópolis, Brasil.

Rocha, A. M. (2011). Divina proporção: aspectos filosóficos, geométricos e sagrados da seção áurea. Fortaleza: Expressão Gráfica Editora.

Rodrigues, D.; Rodrigues, M. H. Desafiando o pensamento geométrico. In Anais do 21 Simpósio de Geometria Descritiva e Desenho Técnico. Florianópolis: v.1, 2013.
Rodrigues, M. H. W. L.; Geometria Gráfica Bidimensional: uma viagem de exploração ao mundo mágico da geometria dinâmica. Educação Gráfica (Bauru), Bauru, v. 9, p. 29-38, 2005.

Sainz, J. (1990). Dibujo de Arquitectura. Madrid: Editora Nerea.

SANEP, Serviço Autônomo de Saneamento de Pelotas, disponível em http://www.pelotas.com.br/sanep/museu-do-saneamento/ agua/caixa-dagua/ Acessado em 23/06/2016

Terzidis, K. (2006). Algorithmic Architecture. Burlington: Elsevier. 